\title{
Cost-Benefit Analysis Developing Offshore Wind Energy in China
}

\author{
Ru Liü, a , Junchao Zhao,b, Hui Li ${ }^{3, \mathrm{C}}$ \\ ${ }^{1}$ Beijing Municipal Institute of Science and Technology Information, China \\ ${ }^{2}$ Beijing Municipal Institute of Science and Technology Information, China \\ ${ }^{3}$ Beijing Municipal Institute of Science and Technology Information, China \\ aliur@bjstinfo.com.cn, ${ }^{b}$ zhaojc@bjstinfo.com.cn, ${ }^{c}$ lih@bjstinfo.com.cn
}

\begin{abstract}
Keywords: offshore wind power, development, benefits, economic effect
Abstract. Compared to onshore wind power, offshore wind power has a relatively short history. The offshore wind potential in China is about 3 times larger than onshore, yet China had not dedicated into offshore wind research and development until recent years. China has the incentive to construct offshore wind farms along its southeast coast. This area is adjacent to China's southeast developed regions where it is highly populated and lacking conventional energy supply. And then, we compare with the cost of offshore wind power and fossil fuel fired generation will show which power generation is more attractive.
\end{abstract}

\section{History Of Offshore Wind Power Development}

Compared to onshore wind power, offshore wind power has a relatively short history. The first offshore wind farm was constructed in Vindeby, Denmark in 1991, with 11 turbines of total capacity of 4.95MW. By the end of 2000, there were in total 30MW offshore wind farms worldwide. In 2002, a wind farm with 80 turbines was built in the North Sea, with a generation capacity of $160 \mathrm{MW}$. By the end of 2005, the world offshore wind farm capacity reached 700MW. By the end of 2007, offshore wind capacity reached $1,080 \mathrm{MW}$, taking $1.5 \%$ share of total installed capacity. $90 \%$ of the capacity is distributed in European countries such as Denmark and the UK [1]. In that year, China, Norway, Spain, and the USA planned to install their first offshore wind farm within the decade.

Offshore wind power is still very new energy technology everywhere. At the beginning of 1970s, some Europe countries came up with offshore wind power thoughts. During 1991 and 2000, Denmark, Netherlands and Sweden have finished the trial-manufacture of the model machine and gained experience in offshore wind power equipments [4].

Started from 1999, the offshore wind farms had a rapid development. More and more countries started to develop in this energy area. The first commercial offshore wind farm was constructed in Copenhagen Denmark, with 20 turbines each has a capacity of 2 MW. As shown in figure 1, there are only 6 offshore wind projects in Europe with a capacity of only 32MW. Until 2007, the industry of Europe had developed 25 projects with a total capacity of about $1232 \mathrm{MW}$ [3]. Most of these offshore wind farms are large-scale and for commercial use. In the year 2008, among the newly added energy capacity in the EU which was 23,851 MW, wind power took the largest share of 36\%. It was the first time in Europe that wind power dominated the energy structure. [2] 


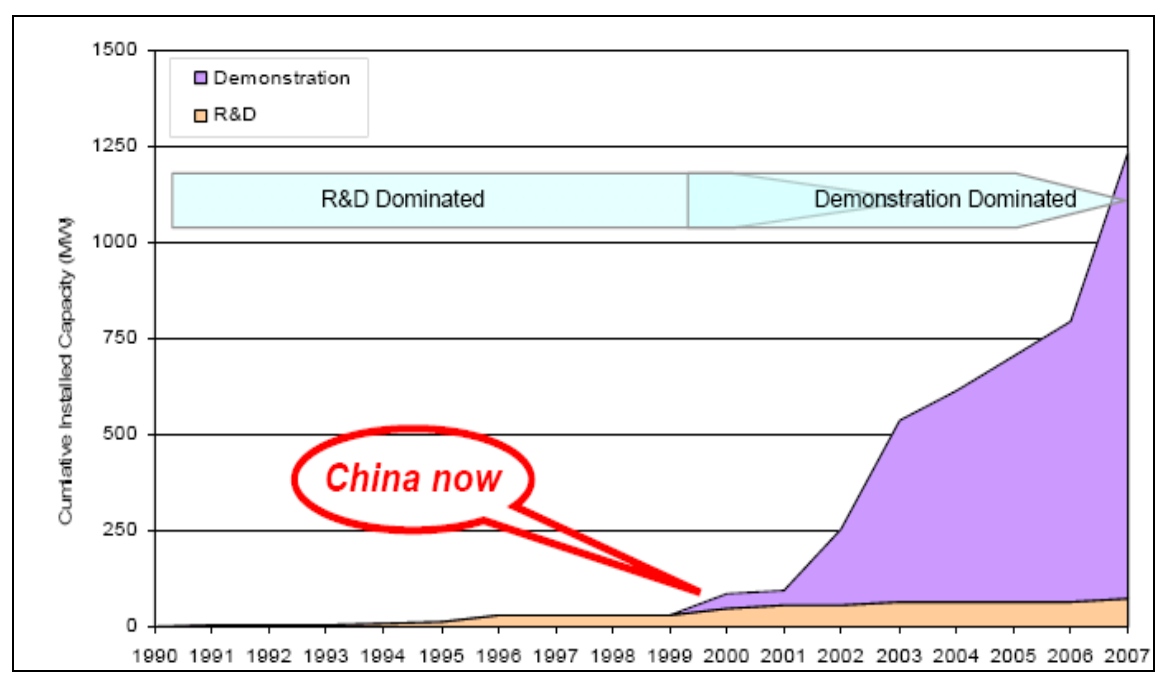

Figure 1: Europe offshore wind power development [3]

Offshore wind in Europe has been developed rapidly during the last decade, installed capacity increased from $32 \mathrm{MW}$ in 1999 to 1,232 MW in 2007. China's offshore wind power development is at the bottom level over the world. About 10-15 GW of installed capacity in Europe can be forecast. Drivers of offshore wind farms are different from country to country. The development of offshore wind power is driven by rich wind resources, experience from onshore wind development, good economic management, and governmental policy.

\section{Offshore Wind Power Foreground In China}

The offshore wind potential in China is about 3 times larger than onshore, yet China had not dedicated into offshore wind research and development until recent years. China has the incentive to construct offshore wind farms along its southeast coast. This area is adjacent to China's southeast developed regions where it is highly populated and lacking conventional energy supply. The first commercial offshore wind turbine in China was installed on East China Sea March 20, 2009. It belongs to Shanghai East China Sea offshore Wind Project which will install 34 wind-driven generators along the Shanghai East China Sea Bridge, each with a capacity of $3 \mathrm{MW}$. The total installed capacity will be $102 \mathrm{MW}$ [5].

Zhe jiang province is in short of energy. Most of its energy depends on neighboring provinces. So Zhe Jiang province makes a policy with exploring offshore wind resource as its key point for its renewable energy development plan [5].

Up to date, China has already sketched out six offshore wind power plans along the east coastline in all: Bohai Suizhong(1.5MW), Hebei(50MW), Dongshan Island(20MW), Nan'ao(20MW), Qingdao(20MW), and Shanghai Donghai Bridge offshore wind farm (100MW). Among them, Bohai Suizhong project is a demonstration project with only one turbine and has been in operation since 2007. Shanghai offshore wind farm is the only project in the East China Sea area and this project is the largest offshore wind project in China. Figure 2 shows the allocation of planned offshore wind farms in China. 


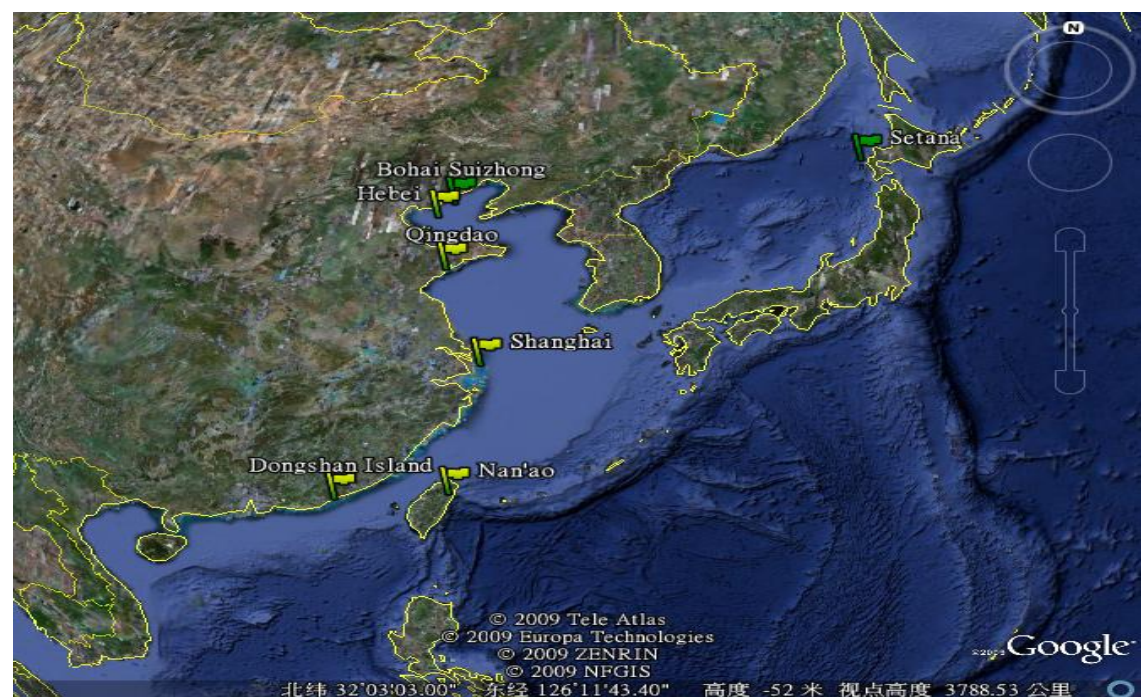

Figure 2: The Chinese offshore wind power mapped by Offshore Center Denmark

Shanghai Donghai Bridge offshore wind farm is the largest commercial offshore wind farm among the 6 planned projects. The Bohai Suizhong wind project is a demonstration project with only one turbine with a capacity of $1.5 \mathrm{MW}$. The other 5 are to be constructed in the near future.

\section{Comparison With Offshore Wind Power And Fossil Fuel Fired Generation}

As a largely untapped energy resource, offshore wind power in China is one of the key projects to address the climate goals and energy demands with lower environmental impact and lower social risk. It will be one of important components in renewable energy resource structure.

Offshore wind power in China is clearly a viable energy power in future. Along with the trend with fuel costs on the rise, any renewable power (like natural gas) with free fuel costs becomes economically viable. And what's more, the coal fire power plant also plays a very important role in China electricity market. To compare with the cost of offshore wind power and fossil fuel fired generation will show which power generation is more attractive.

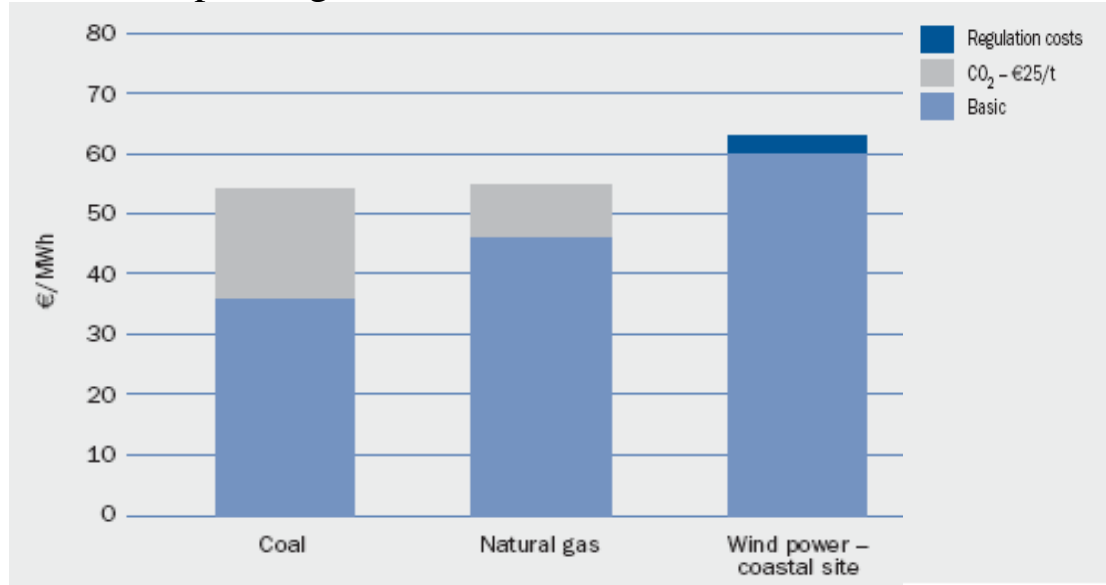

Figure 3: cost of energy comparison with fossil fuel fired generation in 2009[6].

As shown in figure 3, the wind power has the higher capital costs, but there is no fuel cost. It is not an attractive investment compare with coal fired power plant and natural gas power plant in short term. The coal and natural gas power plant produce GHG emission into atmosphere from the environmental aspect. They can not to avoid GHG emission cost. Because the energy shortage of the world and the heavy demand for $\mathrm{CO} 2$ sent the price up in future, a sensitivity analysis is carried as shown in figure 4. 


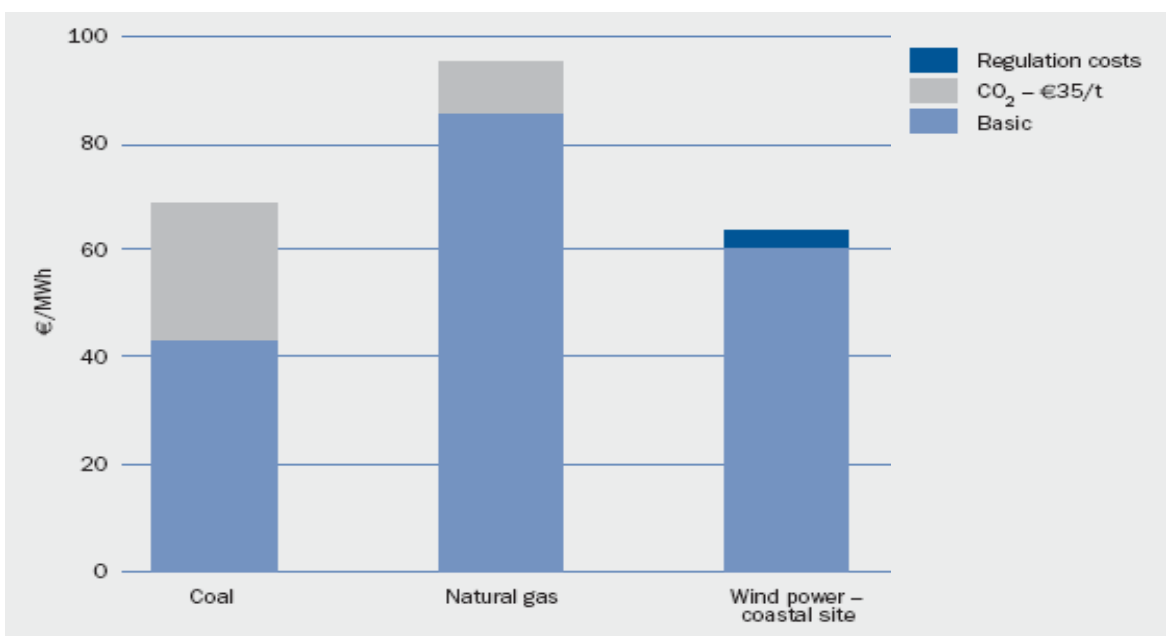

Figure 4: cost of energy comparison with fossil fuel fired generation in future[6].

The natural gas price has rapid increase compared to high oil price in future. And the coal price also increase to 70 Euro per MWh from 55 Euro per MWh in 2009. Thus, offshore wind power is very close to being competitive with rising fuel and carbon prices, not only comparison with onshore farm, but also in comparison with other traditional power stations. Even offshore wind energy is more expensive per KWh, it has a significant attraction compare other fossil fuel fired generation, because it decrease the investment risk and hedges against unexpected rises in cost of oil and CO2 in the future.

\section{Conclusion}

Today, wind power is becoming a competitive energy source for power generation in China, particularly with the passage of a renewable energy law in 2005 and thereafter China has become one of the world's largest markets for wind turbines. Along its eastern coastline, China has a large area of shallow sea in which the estimated offshore wind energy potential is approx. three times larger than onshore potential. This area is extraordinarily promising for wind farm construction because offshore wind speed is higher and more stable than onshore wind, and the wind sites are close to the main load centers of eastern China. China has an intention of expanding offshore wind power generation capacity to $1 \mathrm{GW}$ by 2050[7]. As a largely untapped energy resource, offshore wind power in China is one of the key projects to address the climate goals and energy demands. It will be one of important components in renewable energy resource structure. A fully developed Chinese offshore wind power would enable this new energy to supply roughly a capacity of $750 \mathrm{GW}$ [5] to address our future electricity demands. The ultimate objective of the project is to largely utilize offshore wind resource in the East China Sea and ideally form a network of all the offshore wind farms. If this goal is achieved, the East China Sea will continuously supply relatively constant power to the East China Grid. The generation capacity is estimated to be $1 \mathrm{GW}$. Dependence on coal power plants as well as remote power transmissions can be reduced. The $1 \mathrm{GW}$ goal could be seen as a beacon for China to further develop larger size wind turbines and technologies for construction in the deeper sea to capture more wind power.

The development of offshore wind power in China has several expected results as follow: (1) Wind power causes zero emissions during their life cycle and no environmental damage through resource extraction and waste management. Offshore wind power is a good way to reduce the future carbon and it is expected to play an important role in meeting the Kyoto Protocol. (2) Offshore wind power will play an important role in ensuring indigenous energy supply and reducing fossil fuel imports dependence in the future.(3) Offshore wind power in China will contribute to a more supply of electricity beyond coastal area at east of China, and is a wide variety of supplement in nationwide grid net. (4) Although the good technologies and experience come from EU and USA at present, China has more attracting advantages: Price! Some Asia countries and African countries could import offshore 
wind technologies and experience from China. What's more, China also could import their excess wind energy to some neighboring countries. (5) Offshore wind farm could increase more employment opportunities and higher quality of work; it also could develop regional economy. (6) Offshore wind farm could reduce the electricity prices. Firstly, wind resource is free and wind turbines do not consume any fuel, once the wind farm has been built it makes more attractive electricity prices. Secondly, offshore wind energy produces zero $\mathrm{CO} 2$ emissions which could reduce the cost of carbon permit.

So,the development of offshore wind power in China does not only mean contribute to CO2 reduction, but it is also reduced fossil fuel imports dependence in the future and increases in export opportunities, sustainable local economic growth, high quality job and so on.

\section{References}

[1]Dan Rigden, Todd Westbrook, Offshore wind: will it deliver? http://www.energyinst.org.uk/content/files/danrigden.pdf

[2]EWEA, http://www.ewea.org/index.php?id=1338.( 2009)

[3]Garrad Hassan and Partners Ltd, International Experience and Practice in Offshore Wind Farm Development( 2009)

[4]Hu Qiying, Development status of offshore wind energy technology in Europe( 2005)

[5]Offshore Wind China 2009 Conference, http://www.offshorewindchina.cn/english/ ( 2009)

[6]Soren Krohn, The Economics of Wind Energy, page13, 49, 69, a report by the European Wind Energy Association( 2009)

[7]NDRC, Medium and Long-Term Development Plan for Renewable Energy( 2007) 